\title{
Bio-efficacy of deltamethrin based durable wall lining against wild populations of Anopheles gambiae s.l. in Northern Tanzania
}

\author{
Eliningaya J. Kweka ${ }^{1,2^{*}}$ C , Ming-Chieh Lee ${ }^{3}$, Beda J. Mwang'onde ${ }^{1}$, Filemoni Tenu ${ }^{4}$, Stephen Munga ${ }^{5}$, \\ Epiphania E. Kimaro ${ }^{1}$ and Yousif E. Himeidan ${ }^{6}$
}

\begin{abstract}
Background: Indoor residual spraying (IRS) is one of the preferred tools used for control of malaria in many settings in the world. However, this control tool still faces challenges that include lack of long lasting active ingredient, limited number of well-trained personal, and need of repeated treatment which increases operational costs and reduces acceptability by residents. As a result there is need to develop and validate other methods which can complement the existing controls. The current study compared the bio-efficacy of durable wall lining (DL) (treated with deltamethrin $265 \mathrm{mg} / \mathrm{m}^{2}$ ) and IRS (with deltamethrin 5\% WP at $20 \mathrm{mg} / \mathrm{m}^{2}$ ) on indoor mosquitoes densities and biting behaviour of mosquitoes in comparison with control houses without either DL or IRS.
\end{abstract}

Methods: A study with two treatment arms and a control was conducted in Magugu ward, Northern Tanzania. Overall, a total of 60 houses were selected for the study with 20 houses per treatment arm and control. From each arm and control five houses were selected for mosquitoes trapping. Mosquitoes were sampled from 18:00 to 07:00 hourly every month for a period of 6 months. Mosquitoes were sampled using CDC miniature light traps.

Results: A total of 14,400 female wild mosquitoes were used for contact bioassays in the control arm. 20 houses were sprayed, additionally walls of 20 houses were installed with wall liners, and walls of 20 unsprayed houses were used as control. Also, a total of 946 mosquitoes were sampled with traps in 60 houses during the hourly sampling for 6 months. A total of 3000 unfed females of An. gambiae s.l. wild population raised from larvae were collected from natural habitats in the same village for bioassays. The decline in indoor mosquitoes densities observed in this study did not lead to a shift in the biting cycles $(P=0.712)$. The number of mosquitoes caught indoors in houses with $\mathrm{DL}$ and IRS was significantly lower $(P<0.001)$ compared to control houses. When the comparisons were done between $\mathrm{DL}$ and IRS houses, the densities were significantly lower in DL houses compared to IRS houses $(P=0.021)$. In the DL installed houses, indoor mosquito density declined notably and sustained throughout the 6 months of the study. However, in those houses sprayed with deltamethrin 5\% WP (PAL $\left.{ }^{\mathrm{TM}} 5 \mathrm{WP}\right)$, the density noted to start to increase within four months after spraying(do you mean to say that the densities declined up to 4 months post spraying and thereafter increased.

Conclusions: Considering the efficacy duration of DL against IRS with deltamethrin 5\% WP on mosquito densities decline indoors. The results of this study suggest that $\mathrm{DL}$ is more effective in malaria control as its efficacy lasted more than that of IRS.

Keywords: Durable wall lining, Indoor residual spray, Culicine, Anopheles gambiae s.l., Bioassays, Resistance, Susceptible

\footnotetext{
*Correspondence: kwekae@tpri.or.tz

1 Division of Livestock and Human Diseases Mosquitoes Control,

Mosquito Section, Tropical Pesticides Research Institute, P.O. Box 30214,

Arusha, Tanzania

Full list of author information is available at the end of the article
} 


\section{Background}

Currently, use of long lasting insecticide treated nets (LLINs) and indoor residual spray (IRS) are the preferred tools for mosquitoes control in sub Saharan Africa [1-3]. The main mosquitoes observed in this region are Anopheles gambiae complex sibling species and An. funestus group [4-6]. It has been reported that the biting and host seeking behaviour of An. gambiae s.l. and An. funestus starts at dusk but the frequency increases from 22:00 $\mathrm{h}$ to mid-night. This biting cycle eventually peaks again in the morning starting at 3.00 to 6.00 a.m. [7, 8]. Recent studies have suggested early biting behaviour in An. gambiae s.l., starting from 19:00 and 20:00 $\mathrm{h}$ and this has been attributed to the increased distribution and coverage of LLINs [9].

In Tanzania there has been scaling up of conventionally treated nets and LLINs since 1980s and 2005 respectively [10-12]. In some malaria endemic foci, LLINs have been combined with IRS $[2,13]$ and incidences of malaria have significantly decreased in areas with increased coverage of LLINs use $[3,14]$. More recently there has been concern of the impact of LLIN on mosquitoes as mosquitoes have been found resting indoor in houses treated with LLINs or IRS due to insecticides resistance selection pressure among mosquitoes population hence delayed knockdown on the surface of the net or walls $[15,16]$. This suggests that in areas where the main mosquitoes is An. arabiensis, adding IRS into houses with LLINs does not enhance house-hold level protection except where the IRS employs non-pyrethroid insecticides [2, 17]. More recently durable wall linings (DL) have been produced and this study tested whether they have greater impact in reducing indoor resting mosquitoes compared to normal IRS. The same active ingredient (AI) of deltamethrin was used in both DL and IRS. The DL was incorporated with deltamethrin at a dosage of $265 \mathrm{mg} / \mathrm{m}^{2}$ [3]. The compound used for IRS was PALI ${ }^{\mathrm{TM}} 5 \mathrm{WP}$ (Deltamethrin $5 \% \mathrm{WP}$ ) the dosage is $20 \mathrm{mg} / \mathrm{m}^{2}$ which was diluted in $10 \mathrm{l}$ of water and applied in $250 \mathrm{~m}^{2}$.

The objective of current study was to compare the bioefficacy of durable wall lining (DL) (treated with deltamethrin $265 \mathrm{mg} / \mathrm{m}^{2}$ ) and IRS (with deltamethrin 5\% WP at $20 \mathrm{mg} / \mathrm{m}^{2}$ ) on mosquito indoor mosquitoes densities and biting behaviour in comparison with control houses without either DL or IRS.

\section{Methods}

\section{Study sites}

The study was conducted in, Magugu ward in Babati district (malaria epidemic prone site), Manyara region. This study site is located in the Great Rift Valley of northern Tanzania. Twenty houses were selected (give the basis for selecting the 20 houses-were they randomly selected) for DL installation and other twenty for IRS. Trial houses were labelled and mapped (Fig. 1). Houses were selected based on household agreement. The three arms (i.e. wall liner, IRS and control) were selected clustered together. Twenty houses each in three arms each were selected for follow up during the 6 month study period. Baseline sampling was conducted before treatment in December, 2012. The L1014F mutation in this study area was found in An. arabiensis at the allelic frequency of $11.5 \%$ in Babati by previous study $[10,18]$. In this site, kdr mutations were recorded without obvious phenotypic resistance to pyrethroids being observed $[10,18]$.

\section{Anopheles gambiae s.l. larvae sampling}

Anopheles gambiae s.l. larvae were sampled in breeding sites such as drainage ditches, abandoned brick pits, pottery and tyres obsoletes for six consecutive months. Mosquito larvae specimen were collected using a standard $350 \mathrm{ml}$ dipper (BioQuip Products, Inc. California, USA) and transported to the laboratory and reared to adults in the insectary at the Tropical Pesticides Research Institute, Magugu field station and identified using morphological keys developed by Gillies and Coetzee [19]. The emerged adults were used for the susceptibility tests.

\section{Mosquito indoors sampling by traps}

Twenty houses were selected for each treatment arm and control. Mosquitoes were sampled using CDC miniature light traps from 18:00 to 07:00 hourly monthly for 6 months [20, 21]. Sampling was done from 18:00 to 07:00 $\mathrm{h}$ at hourly interval to monitor the effect of the protective efficacy of control tools on biting cycle and house entry behaviour. The collected mosquitoes were kept in a well labelled paper cup, then transported to the laboratory for morphological species identification [19].

\section{Insecticide susceptibility tests}

Insecticide susceptibility tests were conducted with wild population mosquitoes to ascertain the efficacy of the control tools against wild mosquito populations. Bioassay tests were carried out using the standard WHO protocol [22], using wild and laboratory colony mosquitoes. Insecticide susceptibility test kits and impregnated papers approved by WHOPES with discriminating dosage was used [23]. Larvae were reared in insectary from wild sampled population of $A n$. gambiae s.l. and 2 day old non-blood-fed adult female of An. gambiae s.l. wild population used in the tests. Batches of 25 mosquitoes per replicate were exposed to test papers impregnated with bendiocarb $(0.1 \%)$, DDT (4\%), permethrin $(0.75 \%)$ and deltamethrin $(0.05 \%)$. Each test had four replicates and two controls. Deltamethrin is the active ingredient used in both IRS 


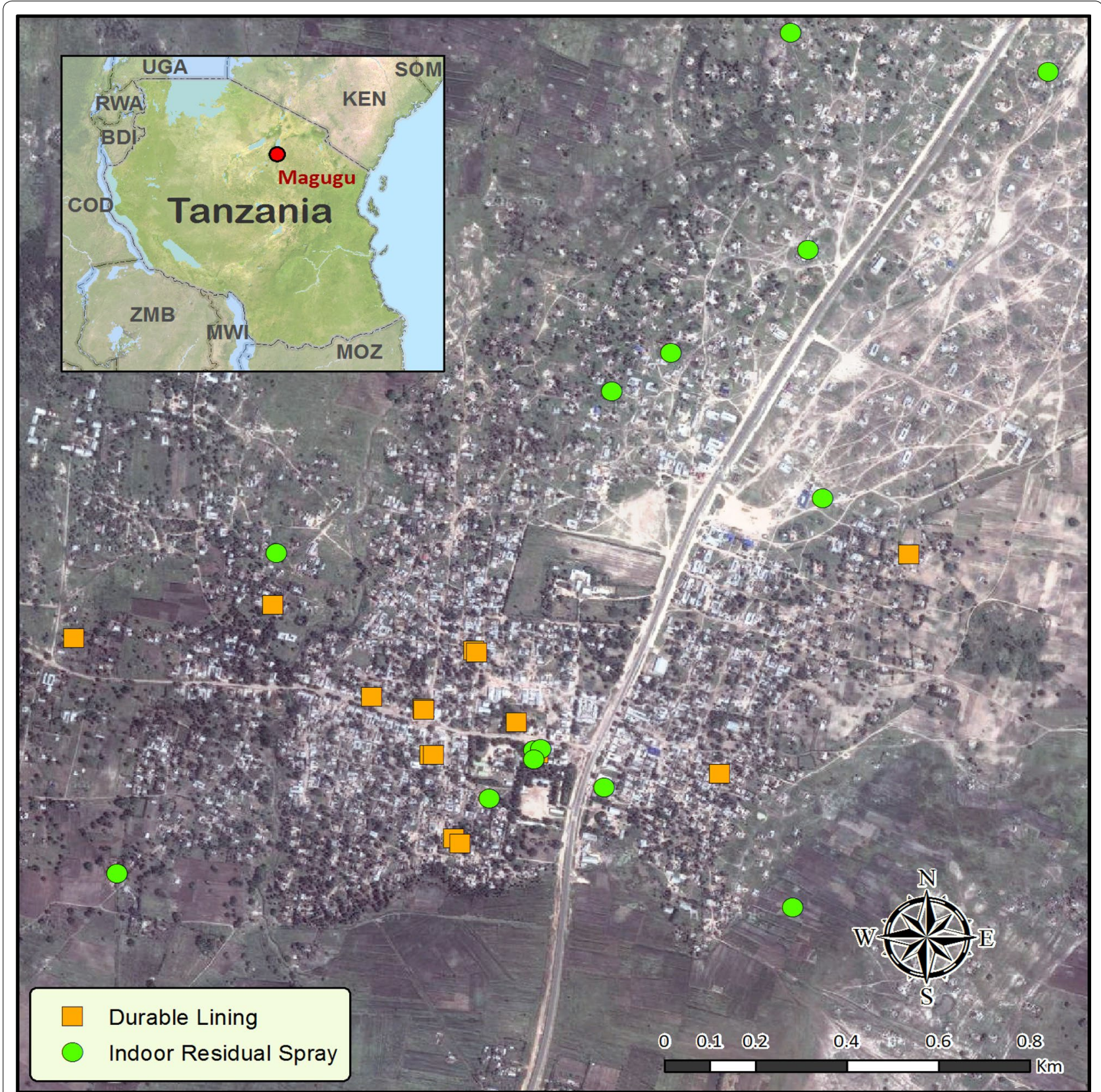

Fig. 1 The map of Tanzania showing the study site in Great Northern Rift Valley of Tanzania (The GIS points are our original work and the background of this map is developed from Google map)

and DL. In the control experiments, wild population of mosquitoes from the same sites were exposed to untreated papers (Standard WHO control papers for each insecticides class). The knockdown effect of each insecticide was recorded in time interval 10, 15, 20, 30 40, 50, 60 min, and mortality recorded 24 h post test as scheduled in WHO protocol. Mosquitoes were then transferred to a paper cup and provided with $10 \%$ glucose solution. Final mortality was recorded $24 \mathrm{~h}$ post-exposure. WHOPES suggests that, if $98-100 \%$ mosquito mortality is observed, this indicate insecticide susceptibility, mortality $<98 \%$ suggests existence of resistance that needs to be confirmed, and mortality $<90 \%$ mortality suggests resistance. All batches of insecticide-impregnated paper (WHOPES approved standard papers) were pre-tested on a laboratory strain of An. gambiae s.s. maintained at the insectary, which is known to be highly susceptible to pyrethroids and DDT. All susceptibility tests were carried out at $26-29^{\circ} \mathrm{C}$ and $74-82 \%$ relative humidity. 


\section{Contact bioassays}

The persistence of biological efficacy of the insecticide formulations on the sprayed surfaces of the houses and those covered by DL was determined by contact bioassays. Wild population of An. gambiae s.l. were exposed to the sprayed walls using standard cones [24]. Into each cone 10 blood-fed mosquitoes, obtained from daytime resting collections in human dwellings and cowsheds of the same village, were released and exposed for $30 \mathrm{~min}$ and then removed using an aspirator. Controls were exposed to an unsprayed surface. Each test batch of mosquitoes was held in a paper cup covered with netting and provided with a cotton pad of glucose solution (10\% sugar solution). Knockdown and mortality was recorded after 1 , and $24 \mathrm{~h}$ respectively at room temperature. When mortality in control exceeded $20 \%$, results were rejected. Bioassay was done in day 1 and thereafter was done monthly for 6 months. The sprayman and head of household were interviewed on the spray day up to 6 months to know the perceived side effects.

\section{Data analysis}

Data analysis was performed using the PWAS statistic version 18.0 (SPSS Inc., Chicago, IL). Due to low number of mosquitoes sampled hourly, the number of mosquitoes were $\log$ transformed $[\log (n+1)]$. One way Analysis of variance (ANOVA) was used to compare mosquitoes 'abundance in the two treatment arms and a control. A paired sample $T$ test, homoscedastic, was used to compare performances between DL and IRS. The proportions of mortality between IRS and DL walls were compared using Chi square test. The time lapse in months between treatment and mosquito population's resurgence was analyzed using generalized linear model (GLM), univariate analysis density being a dependent variable.

\section{Results}

Mosquitoes sampling by CDC light traps

Overall, a total of 946 mosquitoes were collected from the DL, IRS treated and control houses over the 6 month period. Out of the total number sampled, 392 (41.4\%) were Culicine species, 553(58.5\%) An. gambiae s.l. and 1 (0.1\%) An. funestus (Table 1). An. funestus was not included in the analysis because of low proportion visà-vis Culicines and An. gambiae s.l. There were no significant differences $(P>0.05)$ within treated houses in mosquito densities within each treatment arm therefore, all houses were pooled together in respective hours and treatment. The total of 14,400 female An. gambiae s.l. females were used for the contact bioassays in the walls of houses sprayed with deltamethrin, Walls installed with DL and control houses.

\section{Insecticides resistance status}

The deltamethrin and DDT had the lowest knockdown time (KT) in $\mathrm{KT}_{50}$, but higher in $\mathrm{KT}_{90}$ and $\mathrm{KT}_{95}$ (Table 2). Permethrin $(0.75 \%)$ and deltamethrin $(0.05 \%)$ had 86.8 and $98.0 \%$ mortality after $24 \mathrm{~h}$ post exposure, respectively (Table 3).

\section{Mosquito density and biting cycles for 6 months in all three cases hourly}

There was a difference in mosquito numbers in treatment houses soon after intervention conducted with IRS and DL compared to houses without treatment where the density remained higher but the biting frequency of An. gambiae s.l. and Culicine species still remained the same between the two arms (Figs. 2, 3). The mosquitoes biting frequency in hourly interval for An.gambiae s.l. was statistically significant higher in DL than IRS treatments $(\mathrm{t}=2.649 ; \mathrm{df}=14, P=0.021)$, the same trend was observed for Culicine species $(\mathrm{t}=3.186, \mathrm{df}=14, P>0.001)$. In the deltamethrin (IRS)

Table 1 Summary for the mosquito's species sampled with CDC miniature light trap from 18:00 to 07:00 $\mathrm{h}$ before and after the interventions

\begin{tabular}{|c|c|c|c|c|c|c|c|c|c|}
\hline Species & Treatment & December & January & February & March & April & May & June & Total \\
\hline Anopheles funestus & DWL & 1 & 0 & 0 & 0 & 0 & 0 & 0 & 1 \\
\hline Anopheles funestus & IRS & 0 & 0 & 0 & 0 & 0 & 0 & 0 & 0 \\
\hline Anopheles funestus & Control & 0 & 0 & 0 & 0 & 0 & 0 & 0 & 0 \\
\hline Anopheles gambiae s.l. & DWL & 73 & 4 & 0 & 0 & 0 & 0 & 0 & 77 \\
\hline Anopheles gambiae s.l. & IRS & 65 & 5 & 6 & 6 & 7 & 16 & 17 & 122 \\
\hline Anopheles gambiae s.l. & Control & 80 & 35 & 49 & 49 & 42 & 48 & 51 & 354 \\
\hline Culex species & DWL & 37 & 12 & 9 & 2 & 0 & 0 & 0 & 60 \\
\hline Culex species & IRS & 38 & 7 & 16 & 0 & 9 & 15 & 30 & 115 \\
\hline \multirow[t]{2}{*}{ Culex species } & Control & 33 & 39 & 39 & 31 & 38 & 8 & 29 & 217 \\
\hline & & 327 & 102 & 119 & 88 & 96 & 87 & 127 & 946 \\
\hline
\end{tabular}


Table 2 Knockdown time in minutes for An. gambiae s.I. wild population against different insecticides in susceptibility test using WHO kits

\begin{tabular}{|c|c|c|c|c|c|}
\hline \multirow[t]{2}{*}{ Insecticide } & \multicolumn{3}{|c|}{ Knock down time in minutes $(95 \% \mathrm{Cl})$} & \multicolumn{2}{|c|}{ Goodness of fit test } \\
\hline & $\mathrm{KDT}_{50}$ & $\mathrm{KDT}_{90}$ & $\mathrm{KDT}_{95}$ & $x^{2}$ & $P$ value \\
\hline Permethrin $0.75 \%$ & $25.0(17.0-31.9)$ & $62.6(50.5-83.4)$ & $81.2(64.0-117.6)$ & 1101.8 & $<0.001$ \\
\hline Deltamethrin $0.05 \%$ & $23.7(19.1-28.4)$ & $63.5(49.3-98.2)$ & $83.9(61.7-146.1)$ & 1874.9 & $<0.001$ \\
\hline DDT $4 \%$ & $13.5(8.92-17.77)$ & $71.2(66.11-79.21)$ & $92.33(85.44-99.39)$ & 941.55 & $<0.011$ \\
\hline
\end{tabular}

Table $324 \mathrm{~h}$ mortality for Wild population of An. gambiae s.l. after exposure to insecticides (mortality in other insecticides were $100 \%$ after $24 \mathrm{~h}$ )

\begin{tabular}{|c|c|c|c|c|c|}
\hline \multirow[t]{2}{*}{ Insecticide } & \multirow{2}{*}{$\begin{array}{l}\text { Total mosqui- } \\
\text { toes tested }\end{array}$} & \multicolumn{2}{|c|}{24 h mortality } & \multicolumn{2}{|l|}{$95 \% \mathrm{Cl}$} \\
\hline & & Number & $\%$ & Lower & Upper \\
\hline Permethrin $0.75 \%$ & 600 & 521 & 86.8 & 84.1 & 89.5 \\
\hline $\begin{array}{l}\text { Deltamethrin } \\
0.05 \%\end{array}$ & 600 & 588 & 98.0 & 96.9 & 99.1 \\
\hline DDT & 600 & 600 & 100 & - & - \\
\hline
\end{tabular}

sprayed houses, populations of both Culicines and $A n$. gambiae s.l. were similar for the 6 month period of study $(P=0.819)$ (Fig. 4). Similar trend was observed in houses treated with DL $(P=0.214)$ (Fig. 5). In the control houses, the population of An. gambiae s.l. was slightly higher than that of Culicines, yet, the difference was statistically insignificant $(P=0.055)$ (Fig. 6).

\section{Contact bioassays}

The exposed An. gambiae s.l. wild populations on the sprayed and DL surfaces mortality monthly varied significantly (Table 4). Mortality in sprayed surfaces was reduced as time elapsed while DL surfaces had no variation for the exposed mosquitoes for all 6 months (Fig. 7). For all 6 months the comparison between sprayed surface and DL mortalities were found to be significantly different (Fig. 7)

\section{Discussion}

The efficacy shown by DL material against wild population of An. gambiae s.l., is remarkably good for protection in wild population with low resistance frequency of deltamethrin $[25,26]$. The durable wall lining (DL), has been found to have potential impact for mosquitoes control in one of malaria epidemic region of Tanzania. Mosquito densities caught indoor in a month pre interventions was higher than that caught during the six

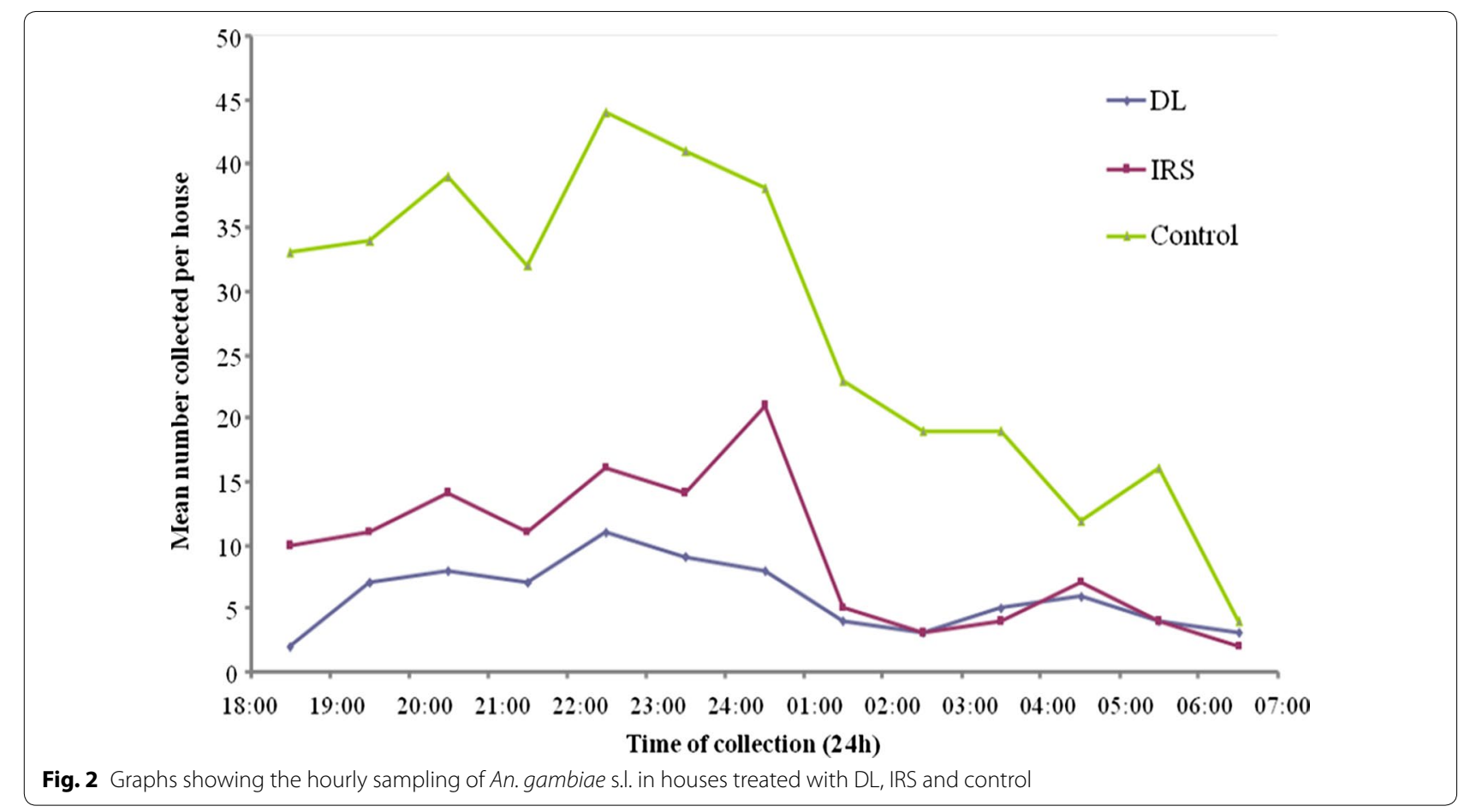




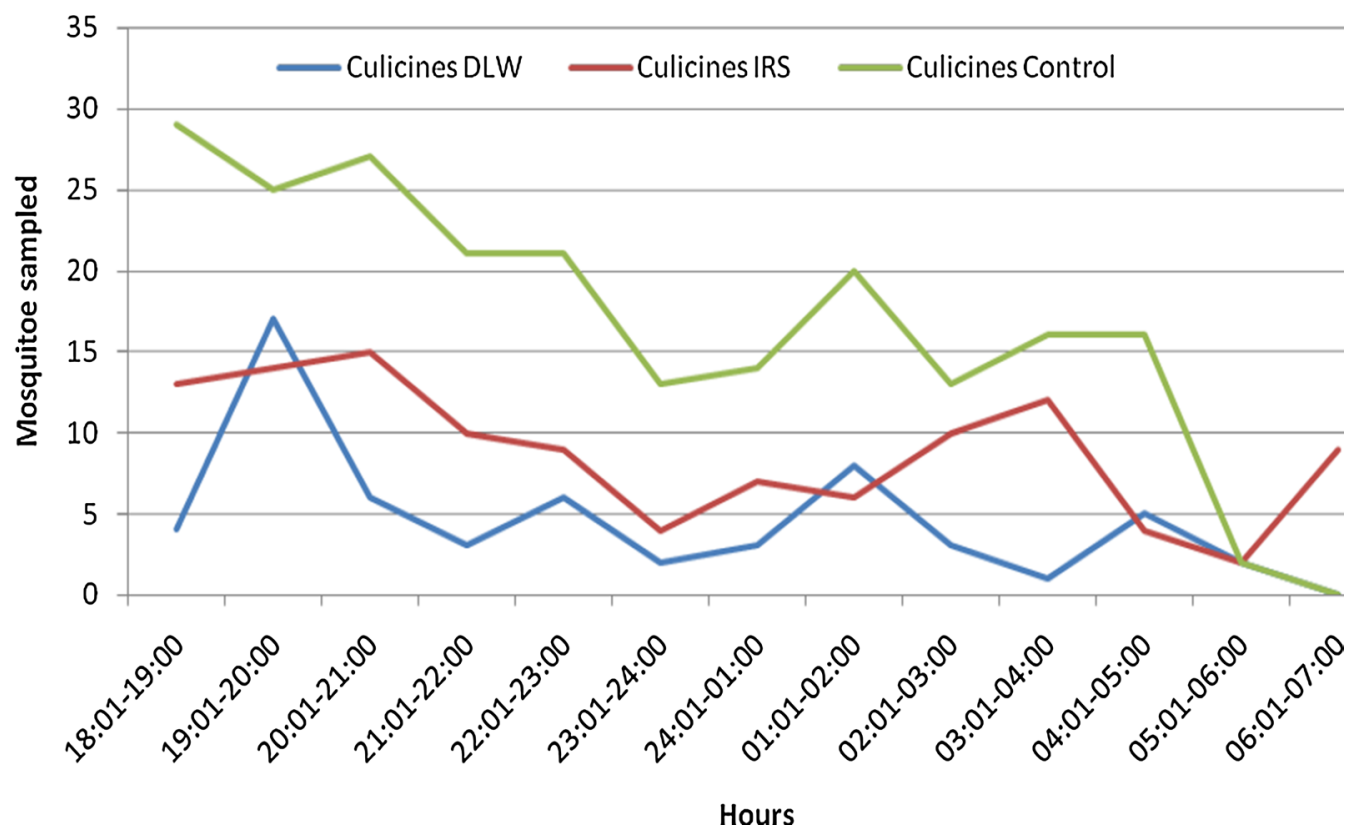

Fig. 3 Graphs showing the hourly sampling of Culicine species in houses treated with DL, IRS and control

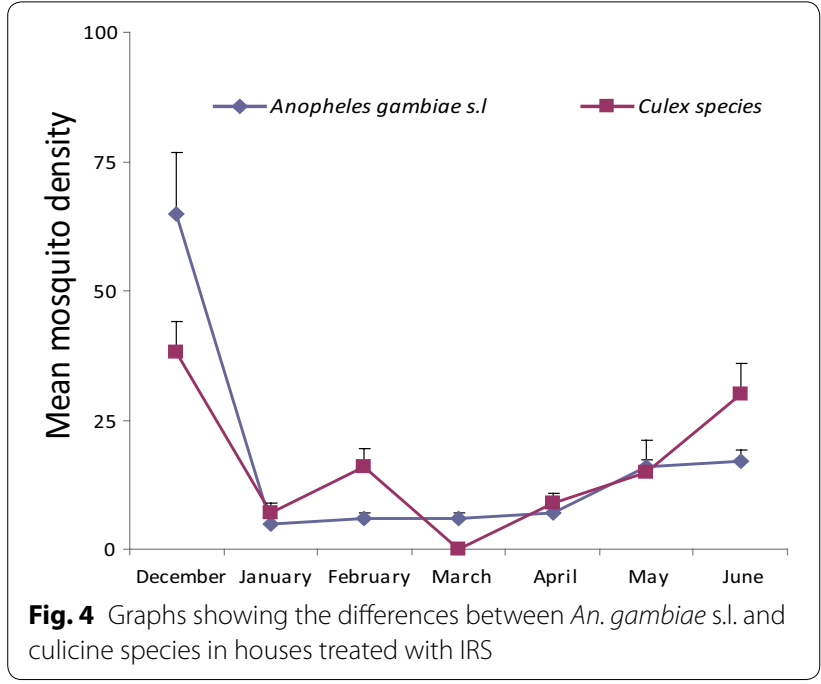

months of intervention. Following introduction of DL and IRS in the selected intervention houses, the decline in mosquito populations was remarkable. This trend was also observed in previous studies where interventions were implemented $[2,3,13,14,27,28]$. Since both DL and IRS were pyrethroid treated, a deterrence effect for mosquitoes getting into these houses was possibly took place, thus contributing to the observed low indoors densities. The reduction in the indoor mosquitoes density indicates the efficacy of the two control tool (IRS and

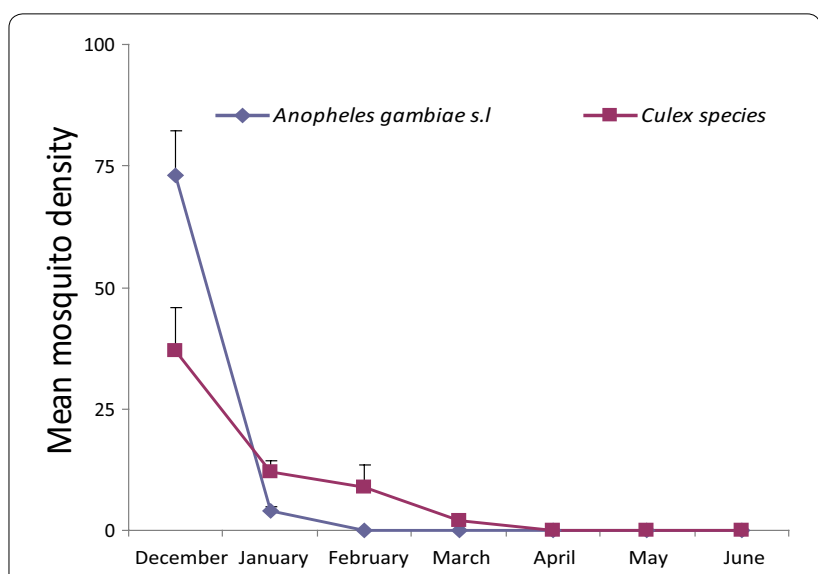

Fig. 5 Graphs showing the differences between An. gambiae s.l. and culicine species dynamics in houses covered with durable wall lining

DL) in controlling mosquitoes. This has been revealed in other studies, which showed that, high pyrethroids intervention tools implementation reduced the proportions of indoor feeding mosquitoes [2, 3]. This can further be confirmed by the fact that, the hourly interval mosquitoes sampling did not show any significant differences in species abundance between An. gambiae s.l. and $C x$. quinquefasciatus in treatment arms and control. In other study conducted parlay to this in Magugu by Mwanziva and other, revealed that $100 \%$ proportion of $A n$. gambiae s.l. is composed of An. arabiensis [18]. Host seeking 


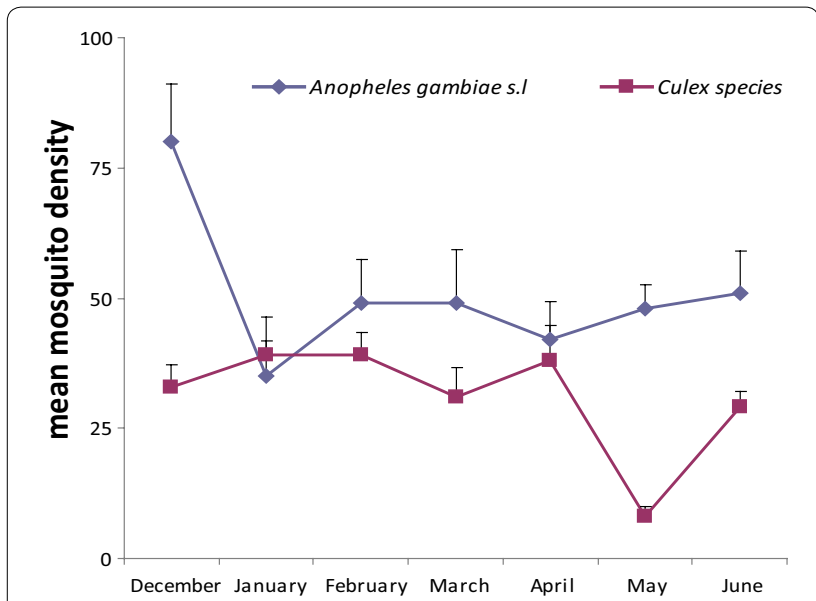

Fig. 6 Graphs showing the differences between An. gambiae s.l. and culicine species dynamics in control houses

behaviour trend indoors did not change the peak time in treatment arms as they matched with control in spite of low density. This indicates that, intervention tools can reduce indoor resting mosquitoes population and did not changed the host seeking behaviour pattern of mosquitoes. This indicated that An. gambiae s.l. is naturally feed indoor but then deterred away after entering the house by indoor pyrethroids intervention to rest outdoor. This pattern of biting behavior has great implication on malaria transmission and it may somehow explain why we still have residual transmission going on despite the high coverage achieved. Similar observation has been reported in Ethiopia [9] and Sudan [17]. These findings are not contrary to what was found in Solomon Islands after DDT spray where An. minimus shifted from earlier hours host seeking in the morning to earlier hours of evening [29]. This is because that both DDT and pyrethroids insecticides possess strong deterrence efficacy.

Evaluation of resistance status of the wild population of An. gambiae s.l. in study area using WHO standard Kits, have revealed that, the population of $A n$. gambiae s.l. have started showing indicators of resistance against permethrin, and deltamethrin which had highest knockdown time at $\mathrm{KT}_{50}(25,23.7$ and $8 \mathrm{~min})$ and $\mathrm{KT}_{95}$ (83.9 81.2 and $10 \mathrm{~min}$ ), respectively. DDT had higher knockdown time for $95 \%$ population to be knocked down (113.8 $\mathrm{min}$ ) which shows to have threat of being tolerated by mosquitoes. This situation poses threat of cross-resistance and a single point mutation encoding the voltage-gated sodium channel which is now common mechanism of resistance in pyrethroids and DDT $[30,31]$. After $24 \mathrm{~h}$ post exposure, the mortality was found to be 86.8 and $98 \%$ in permethrin and deltamethrin, respectively. These results indicated presence resistance to permethrin and an alert for deltamethrin. This situation needs further large scale study to justify resistance and susceptibility according to the updated WHOPES criteria for reporting of resistance and susceptibility data In spite of the new technology, intervention material which covers whole wall surface indoor, the threat of indoor malaria transmission might go on as resistance develops among mosquitoes species.

Table 4 Contact bioassays and mortality response for different surfaces with different treatments

\begin{tabular}{|c|c|c|c|c|c|c|c|c|}
\hline Month & Surface & & $\begin{array}{l}\text { Number } \\
\text { died }\end{array}$ & $\%$ Mortality & $\begin{array}{l}\text { Lower } \\
95 \% \mathrm{Cl}\end{array}$ & $\begin{array}{l}\text { Upper } \\
95 \% \text { Cl }\end{array}$ & $\mathbf{F}$ & $P$ value \\
\hline \multirow[t]{3}{*}{ Jan-12 } & Unsprayed (control) & 800 & 0 & 0 & 0 & 0 & & \\
\hline & Sprayed & 800 & 800 & 100 & 0 & 0 & 151.18 & $<0.0001$ \\
\hline & $\mathrm{DL}$ & 800 & 800 & 100 & 0 & 0 & 151.18 & $<0.0001$ \\
\hline \multirow[t]{3}{*}{ Feb-12 } & Unsprayed (control) & 800 & 6 & 0.75 & 0.55 & 0.97 & & \\
\hline & Sprayed & 800 & 796 & 99.5 & 99 & 100 & 195.03 & $<0.0001$ \\
\hline & $\mathrm{DL}$ & 800 & 800 & 100 & 0 & 0 & 197.02 & $<0.0001$ \\
\hline \multirow[t]{3}{*}{ Mar-12 } & Unsprayed (control) & 800 & 0 & 0 & 0 & 0 & & \\
\hline & Sprayed & 800 & 798 & 99.75 & 99.21 & 100 & 199 & $<0.0001$ \\
\hline & $\mathrm{DL}$ & 800 & 800 & 100 & 0 & 0 & 200 & $<0.0001$ \\
\hline \multirow[t]{3}{*}{ Apr-12 } & Unsprayed (control) & 800 & 0 & 0 & 0 & 0 & & \\
\hline & Sprayed & 800 & 693 & 86.63 & 74.33 & 98.82 & 152.83 & $<0.0001$ \\
\hline & $\mathrm{DL}$ & 800 & 800 & 100 & 0 & 0 & 200 & $<0.0001$ \\
\hline \multirow[t]{3}{*}{ May-12 } & Unsprayed (control) & 800 & 3 & 0.38 & 0.24 & 0.5 & & \\
\hline & Sprayed & 800 & 638 & 79.75 & 68.65 & 90.82 & 131.17 & $<0.0001$ \\
\hline & $\mathrm{DL}$ & 800 & 800 & 100 & 0 & 0 & 198.49 & $<0.0001$ \\
\hline \multirow[t]{3}{*}{ Jun-12 } & Unsprayed (control) & 800 & 8 & 1 & 0.61 & 1.39 & & \\
\hline & Sprayed & 800 & 624 & 78 & 71.2 & 87.2 & 124.05 & $<0.0001$ \\
\hline & $\mathrm{DL}$ & 800 & 799 & 99.88 & 99.8 & 100 & 195.56 & $<0.0001$ \\
\hline
\end{tabular}




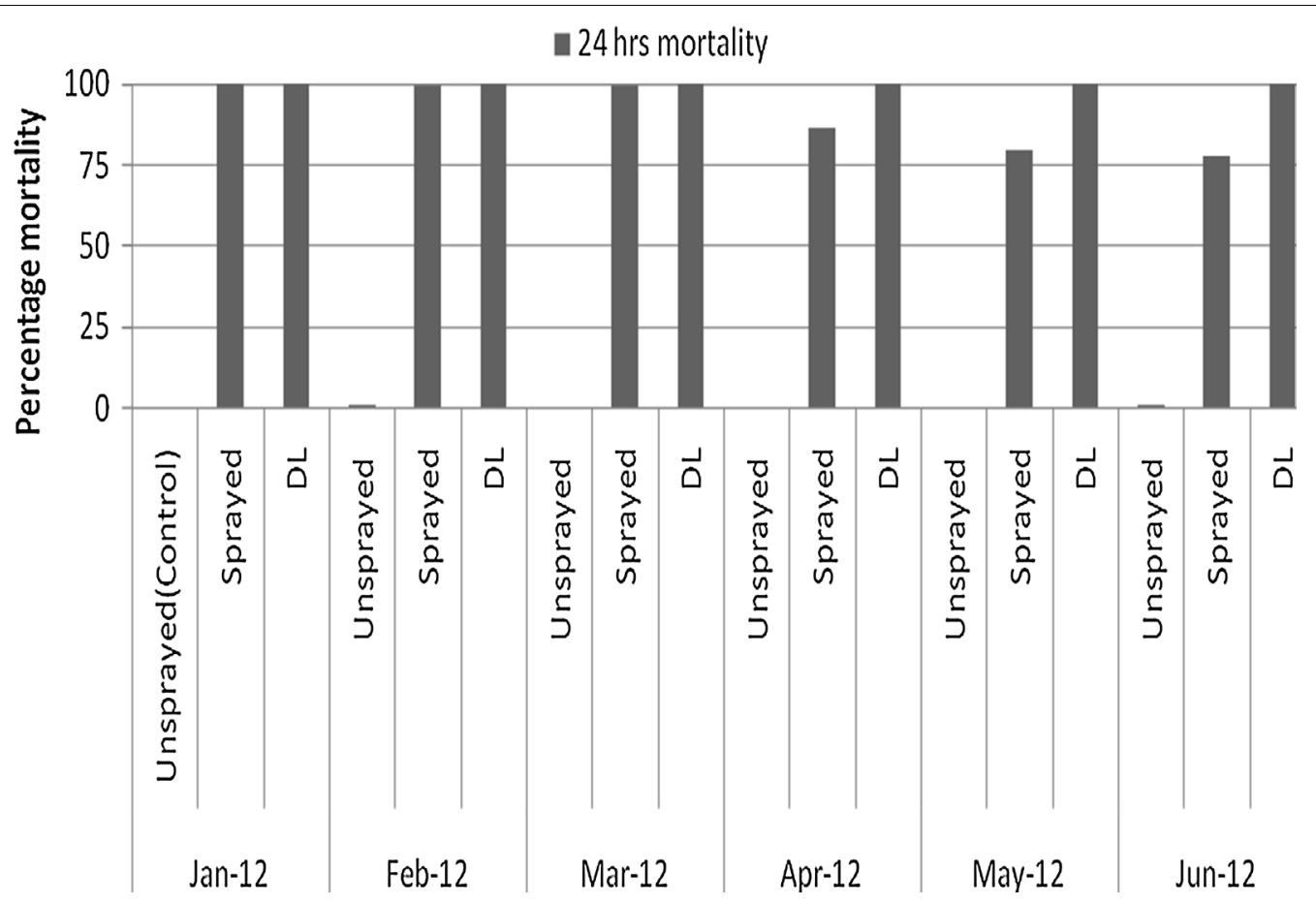

Fig. 7 Twenty four hours ( $24 \mathrm{~h}$ ) cone bioassay mortality of wild population of An. gambiae s.l. after exposure on sprayed walls and walls with DL

The threat posed by deltamethrin and permethrin still of worrisome as these insecticides are widely used for IRS and LLINs for community mosquitoes control [32].

The epidemiological effect of the increased exophily in mosquito population due to pyrethroids indoor intervention has increased a transmission risk to outdoor and unprotected population. It has been observed in areas with high intervention coverage, mosquitoes are more exophagic than endophagic [2, 3, 33]. From this study, it shows that pyrethroids DL and IRS intervention tools once well used can lead to mosquitoes densities reduction indoors. This shall reduce indoor malaria transmissions. Nevertheless, according to Padonou and others [3], the scenario subsequently reduce disease transmission and increase risk to unprotected outdoors [33]. With this, personal repellents like N,N-Diethyl-3-methylbenzamide, menthol propyleneglycol carbonate can protect human from the risk of outdoor malaria transmission [34-36]. The use of mass trapping systems baited with human odours which attracts mosquitoes $[37,38]$ is of paramount importance in mosquitoes reduction outdoors. These traps might have value to mosquitoes control by incorporating bio pesticides in the systems such as fungi which have shown to cause high mortality in infected mosquitoes $[39,40]$. The use of zoo prophylaxis have shown to have efficacy in areas with higher proportion of zoophilic mosquitoes [41]. The population reduction was attained after regular application of insecticides on cattle [42]. The number of animals kept outdoors has found significantly reducing $A n$. arabiensis population indoors [43]. Therefore it's important to consider combination of methods but with a right active ingredient and formulations in mosquitoes control as mosquitoes have greatly changed their traditional way of feeding and resting behaviour.

\section{Conclusion}

In the light of these findings the selection of DL should be incorporated in integrated approach to malaria control for better protection. Further trials should be done in areas with higher mosquitoes population resistant to deltamethrin.

\section{Abbreviations}

DL: durable lining; IRS: indoor residual spray; LLINs: long lasting insecticidal nets; WHOPES: WHO Pesticide Evaluation Scheme; DDT: dichloro diphenyl trichloroethane; KT: knockdown time; GLM: generalized linear model.

\section{Authors' contributions}

EJK conceived and designed the study. EJK, MC, FT and BJM carried out experiments. EJK, MC and FT did data analysis. EJK and EEK drafted this paper. SM, EJK, BJM, YH, MC and FT reviewed the manuscript. YH, EJK critically reviewed and improved the paper. All authors agreed upon submission. All authors read and approved the final manuscript. 


\section{Author details}

${ }^{1}$ Division of Livestock and Human Diseases Mosquitoes Control, Mosquito Section, Tropical Pesticides Research Institute, P.O. Box 30214, Arusha, Tanzania. ${ }^{2}$ Department of Medical Parasitology and Entomology, Catholic University of Health and Allied Sciences, P.O. Box 1464, Mwanza, Tanzania. ${ }^{3}$ Program in Public Health, College of Health Sciences, University of California Irvine, Irvine, CA, USA. ${ }^{4}$ Amani Medical Research Centre, National Institute for Medical Research, P.O. Box 81, Muheza, Tanzania. ${ }^{5}$ Centre for Global Health Research, Kenya Medical Research Institute, P.O.Box 1578, Kisumu, Kenya. ${ }^{6}$ Africa Technical Research Centre, Mosquitoes Health International, P.O. Box 15500, Arusha, Tanzania.

\section{Acknowledgements}

Authors wish to acknowledge Magugu residents whose houses were involved in this study. The study was part of main study of evaluating durable wall lining and IRS funded by Vestergaard Fradensen.

\section{Competing interests}

The authors declare that they have no competing interests.

\section{Availability of data and materials}

All the data regarding the findings are available within the manuscript. Also the raw data is availed on open science framework at osf.io/63r4d.

\section{Consent to participate}

Each individual participated gave the written consent with the witness who was not member of the study.

\section{Ethics approval and consent to participate}

Study approval was given by Tropical Pesticides Research Institute Ethical Review Committee and Tanzania Pesticides Registrar office gave approval for experimental trial in Tanzania on October, 2011. Community meeting was held in Magugu ward for community consent.

\section{Funding}

This study had financial support from Vestgaard Fradensen.

Received: 6 May 2016 Accepted: 2 February 2017

Published online: 10 February 2017

\section{References}

1. Killeen GF, Okumu FO, N'Guessan R, Coosemans M, Adeogun A, Awolola S, Etang J, Dabire RK, Corbel V. The importance of considering community-level effects when selecting insecticidal malaria vector products. Parasit Vectors. 2011:4:160

2. Okumu FO, Kiware SS, Moore SJ, Killeen GF. Mathematical evaluation of community level impact of combining bed nets and indoor residual spraying upon malaria transmission in areas where the main vectors are Anopheles arabiensis mosquitoes. Parasit Vectors. 2013:6:17.

3. Padonou GG, Sezonlin M, Osse R, Aizoun N, Oke-Agbo F, Oussou O, Gbedjissi G, Akogbeto M. Impact of three years of large scale indoor residual spraying (IRS) and insecticide treated nets (ITNs) interventions on insecticide resistance in Anopheles gambiae s.l. in Benin. Parasit Vectors. 2012;5:72

4. Kweka EJ, Mahande AM, Nkya WM, Assenga C, Lyatuu EE, Nyale E, Mosha FW, Mwakalinga SB, Temu EA. Vector species composition and malaria infectivity rates in Mkuzi, Muheza District, north-eastern Tanzania. Tanzan J Health Res. 2008:10:46-9.

5. Mnzava AE, Kilama WL. Observations on the distribution of the Anopheles gambiae complex in Tanzania. Acta Trop. 1986:43(3):277-82.

6. Temu EA, Minjas JN, Tuno N, Kawada H, Takagi M. Identification of four members of the Anopheles funestus (Diptera: Culicidae) group and their role in Plasmodium falciparum transmission in Bagamoyo coastal Tanzania. Acta Trop. 2007;102:119-25.

7. Haddow AJ. The mosquitoes of Bwamba County, Uganda; the vertical distribution of mosquitoes in a banana plantation and the biting cycle of Aedes (Stegomyia) simpsoni, Theo. Bull Entomol Res. 1945;36:297-304.
8. Maxwell CA, Wakibara J, Tho S, Curtis CF. Malaria-infective biting at different hours of the night. Med Vet Entomol. 1998;12:325-7.

9. Yohannes M, Boelee E. Early biting rhythm in the Afro-tropical vector of malaria, Anopheles arabiensis, and challenges for its control in Ethiopia. Med Vet Entomol. 2012;26:103-5.

10. Magesa SM, Wilkes TJ, Mnzava AEP, Njunwa KJ, Myamba J, Kivuyo MDP, Hill N, Lines JD, Curtis CF. Trial of pyrethroid impregnated bednets in an area of Tanzania holoendemic for malaria part 2. Effects on the malaria vector population. Acta Trop. 1991;49:97-108.

11. Magesa S, Lengeler C, deSavigny D, Miller J, Njau R, Kramer K, Kitua A, Mwita A. Creating an "enabling environment" for taking insecticide treated nets to national scale: the Tanzanian experience. Malar J. 2005;4:34.

12. Njunwa KJ, Lines JD, Magesa SM, Mnzava AE, Wilkes TJ, Alilio M, Kivumb K, Curtis CF. Trial of pyrethroid impregnated bednets in an area of Tanzania holoendemic for malaria. Part 1. Operational methods and acceptability. Acta Trop. 1991;49:87-96.

13. Okumu FO, Moore SJ. Combining indoor residual spraying and insecticide-treated nets for malaria control in Africa: a review of possible outcomes and an outline of suggestions for the future. Malar J. 2012;10:208.

14. Antonio-Nkondjio C, Demanou M, Etang J, Bouchite B. Impact of cyfluthrin (Solfac EW050) impregnated bed nets on malaria transmission in the city of Mbandjock: lessons for the nationwide distribution of longlasting insecticidal nets (LLINs) in Cameroon. Parasit Vectors. 2013;6:10.

15. Chareonviriyaphap T, Bangs M, Suwonkerd W, Kongmee M, Corbel V, Ngoen-Klan R. Review of insecticide resistance and behavioral avoidance of vectors of human diseases in Thailand. Parasit Vectors. 2013;6:280.

16. Bradley J, Matias A, Schwabe C, Vargas D, Monti F, Nseng G, Kleinschmidt I. Increased risks of malaria due to limited residual life of insecticide and outdoor biting versus protection by combined use of nets and indoor residual spraying on Bioko Island, Equatorial Guinea. Malar J. 2012;11:242.

17. Haridi AM. Partial exophily of Anopheles gambiae species B in the Khashm Elgirba area in Eastern Sudan. Bull World Health Organ. 1972;46(1):39-46.

18. Mwanziva CE, Kitau J, Tungu PK, Mweya CN, Mkali H, Ndege CM, Sangas A, Mtabho C, Lukwaro C, Azizi S, Myamba J, Chilongola J, Magesa SM, Shekalaghe S, Mosha FW. Transmission intensity and malaria vector population structure in Magugu, Babati District in Northern Tanzania. Tanzan J Health Res. 2011;13:54-61.

19. Gillies T, Coetzee M. Supplement of the Anopheles of Africa South of Sahara (Afrotropical Region). Johannesburg: Republic of South Africa Publication of The South African Institute of Medical Research; 1987.

20. Mboera LE, Kihonda J, Braks MA, Knols BG. Short report: influence of centers for disease control light trap position, relative to a human-baited bed net, on catches of Anopheles gambiae and Culex quinquefasciatus in Tanzania. Am J Trop Med Hyg. 1998:59(4):595-6.

21. World Health Organization. Manual on practical entomology in malaria Part II. Geneva: WHO Division of Malaria and Other Parasitic Diseases; 1975

22. World Health Organization. Guidelines for testing mosquito adulticides for indoor residual spraying and treatment of mosquito nets. Geneva: World Health Organization; 2006.

23. World Health Organisation. Test procedures for insecticide resistance monitoring in malaria vector mosquitoes. Geneva: World Health Organisation; 2013.

24. Mutagahywa J, ljumba JN, Pratap HB, Molteni F, Mugarula FE, Magesa SM, Ramsan MM, Kafuko JM, Nyanza EC, Mwaipape O, Rutta JG, Mwalimu CD, Ndong I, Reithinger R, Thawer NG, Ngondi JM. The impact of different sprayable surfaces on the effectiveness of indoor residual spraying using a micro encapsulated formulation of lambda-cyhalothrin against Anopheles gambiae s.s. Parasit Vectors. 2015;8:1-7.

25. Ngufor C, Tchicaya E, Koudou B, N'Fale S, Dabire R, Johnson P, Ranson $H$, Rowland M. Combining organophosphate treated wall linings and long-lasting insecticidal nets for improved control of pyrethroid resistant Anopheles gambiae. PLoS ONE. 2014;9:e83897.

26. Ngufor C, Chouaïbou M, Tchicaya E, Loukou B, Kesse N, N'Guessan R, Johnson P, Koudou B, Rowland M. Combining organophosphate-treated wall linings and long-lasting insecticidal nets fails to provide additional control over long-lasting insecticidal nets alone against multiple insecticide-resistant Anopheles gambiae in Côte d'Ivoire: an experimental hut trial. Malar J. 2014:13:1-10. 
27. Osse R, Aikpon R, Padonou GG, Oussou O, Yadouleton A, Akogbeto M. Evaluation of the efficacy of bendiocarb in indoor residual spraying against pyrethroid resistant malaria vectors in Benin: results of the third campaign. Parasit Vectors. 2012;5:163.

28. Overgaard HJ, Reddy VP, Abaga S, Matias A, Reddy MR, Kulkarni V, Schwabe C, Segura L, Kleinschmidt I, Slotman MA. Malaria transmission after five years of vector control on Bioko Island, Equatorial Guinea. Parasit Vectors. 2012;5:253.

29. Taylor B. Changes in feeding behaviour of a malaria vector, Anopheles farauti Lav., following use of DDT as a residual spray in houses in the British Solomon Islands Protectorate. Trans Royal Entomol Soc. 1975;127:277-92.

30. Pinto J, Lynd A, Vicente JL, Santolamazza F, Randle NP, Gentile G, Moreno M, Simard F, Charlwood JD, do Rosario VE, Caccone A, Della Torre A, Donnelly MJ. Multiple origins of knockdown resistance mutations in the Afrotropical mosquito Anopheles gambiae. PLoS ONE. 2007;2:e1243.

31. Abdulla S, Schellenberg JA, Nathan R, Mukasa O, Marchant T, Smith T, Tanner M, Lengeler C. Impact on malaria morbidity of a programme supplying insecticide treated nets in children aged under 2 years in Tanzania: community cross sectional study. BMJ. 2001;322:270-3.

32. Aïzoun N, Aïkpon R, Padonou GG, Oussou O, Oké-Agbo F, Gnanguenon V, Ossè R, Akogbéto M. Mixed-function oxidases and esterases associated with permethrin, deltamethrin and bendiocarb resistance in Anopheles gambiae s.l. in the south-north transect Benin, West Africa. Parasit Vectors. 2013:6:1-11.

33. Russell TL, Govella NJ, Azizi S, Drakeley CJ, Kachur SP, Killeen GF. Increased proportions of outdoor feeding among residual malaria vector populations following increased use of insecticide-treated nets in rural Tanzania. Malar J. 2010;10:80.

34. Dekker T, Ignell R, Ghebru M, Glinwood R, Hopkins R. Identification of mosquito repellent odours from Ocimum forskolei. Parasit Vectors. 2011;4:183.

35. Kweka EJ, Mosha FW, Lowassa A, Mahande AM, Mahande MJ, Massenga CP, Tenu F, Lyatuu EE, Mboya MA, Temu EA. Longitudinal evaluation of Ocimum and other plants effects on the feeding behavioral response of mosquitoes (Diptera: Culicidae) in the field in Tanzania. Parasit Vectors. 2008;1:42.

36. Kweka EJ, Munga S, Mahande AM, Msangi S, Mazigo HD, Adrias AQ, Matias JR. Protective efficacy of menthol propylene glycol carbonate compared to N, N-diethyl-methylbenzamide against mosquito bites in Northern Tanzania. Parasit Vectors. 2012;5:189.

37. Govella NJ, Chaki PP, Mpangile JM, Killeen GF. Monitoring mosquitoes in urban Dar es Salaam: evaluation of resting boxes, window exit traps, CDC light traps, Ifakara tent traps and human landing catches. Parasit Vectors. 2011;4:40.

38. Kweka EJ, Mwang'onde BJ, Mahande AM. Optimization of odour-baited resting boxes for sampling malaria vector, Anopheles arabiensis Patton, in arid and highland areas of Africa. Parasit Vectors. 2010;3:75.

39. Bukhari T, Takken W, Koenraadt CJ. Development of Metarhizium anisopliae and Beauveria bassiana formulations for control of malaria mosquito larvae. Parasit Vectors. 2011;4:23.

40. Kamareddine L, Fan Y, Osta MA, Keyhani NO. Expression of trypsin modulating oostatic factor (TMOF) in an entomopathogenic fungus increases its virulence towards Anopheles gambiae and reduces fecundity in the target mosquito. Parasit Vectors. 2013;6:22.

41. Mahande A, Mosha F, Mahande J, Kweka E. Feeding and resting behaviour of malaria vector, Anopheles arabiensis with reference to zooprophylaxis. Malar J. 2007;6:100

42. Mahande AM, Mosha FW, Mahande JM, Kweka EJ. Role of cattle treated with deltamethrine in areas with a high population of Anopheles arabiensis in Moshi, Northern Tanzania. Malar J. 2007;6:109.

43. Tirados I, Gibson G, Young S, Torr SJ. Are herders protected by their herds? An experimental analysis of zooprophylaxis against the malaria vector Anopheles arabiensis. Malar J. 2012;10:68.

\section{Submit your next manuscript to BioMed Central and we will help you at every step:}

- We accept pre-submission inquiries

- Our selector tool helps you to find the most relevant journal

- We provide round the clock customer support

- Convenient online submission

- Thorough peer review

- Inclusion in PubMed and all major indexing services

- Maximum visibility for your research

Submit your manuscript at www.biomedcentral.com/submit
O Biomed Central 